\title{
Optimization Model for Planning Natural Gas Purchases, Transportation, Storage, and Deliverability
}

\author{
Anthony E. Bopp \\ Department of Health Sciences, \\ James Madison University, \\ Harrisonburg, VA 22807, USA \\ Senior Economist, C.C. Pace Resources, Fairfax, VA 22033, USA
}

Vijay R. Kannan

Susan W. Palocsay

Scott P. Stevens

Information \& Decision Sciences Department

James Madison University

Harrisonburg, VA 22807, USA

Fax: (540) 5683273

Corresponding Author: Vijay R. Kannan

An Optimization Model for Planning Natural Gas Purchases, Transportation, Storage, and Deliverability

\begin{abstract}
Natural gas local distribution companies (LDCs) face the problem of managing natural gas purchases under conditions of uncertain demand and frequent price change. In this paper, we present a stochastic optimization model to solve this problem. Unlike other models, this model explicitly considers deliverability, the rate at which gas can be added to and withdrawn from a storage facility, as a variable, and considers its role in ensuring a secure supply of gas. Deliverability is often overlooked in gas supply planning, yet is a critical factor in achieving a secure gas supply. Using data from an LDC in Huntsville, Alabama, we show how this model can be used to minimize total cost while meeting constraints regarding the security of gas supply. We also demonstrate that security is dependent on the rate of deliverability, which in turn is affected by a number of factors including gas availability, storage and transportation considerations, and weather conditions.
\end{abstract}

Key words: Linear programming, stochastic programming, sensitivity analysis, energy, oil industry, inventory control 


\section{INTRODUCTION}

In order to provide service to their customers, natural gas local distribution companies (LDCs) purchase natural gas from gas suppliers, storage capacity so they can inventory gas, and transportation capacity to physically distribute the gas. Their primary concern in planning purchases is to maintain a secure flow of natural gas, meaning that residential, commercial, and industrial customers, and electric utilities will not have their supply of gas curtailed. The fear of any LDC is that on a given day it will not be able to deliver gas to some of its customers. To secure this flow, the LDC can take a number of steps. It can make guaranteed or firm purchases of gas and transportation in advance of demand. The possibility might also exist to store gas to use in the event of increased demand. LDCs can also influence the rate at which they can make changes to the amount of gas stored, or the rate of deliverability. Deliverability is defined as the maximum amount of gas that can be withdrawn from or injected into storage each day. Though deliverability is a critical aspect of gas supply planning, it is often overlooked or subsumed in decisions regarding storage capacity. However, deliverability is itself a decision variable whose value LDCs can influence when managing their inventory of gas.

A competing issue facing LDC decision makers is cost. To guarantee supplies of gas and availability of transportation, LDCs must effectively pay a premium. They can purchase gas on a spot basis each period at spot prices which could be lower than firm prices. Spot prices, however, cannot be determined in advance. In addition, gas availability at the spot price is by no means certain, nor can the quantity available be predicted. Similarly, transportation capacity can be purchased on an interruptible basis each period at a potentially lower cost than for firm purchases, but again, availability and capacity are neither guaranteed nor predictable in advance.

LDC decision makers are thus faced with a dilemma. At the beginning of winter when plans must be made, costs are an important consideration. However, on a given day during a very cold winter, costs would seem to be less important than security. Managers would be willing to spare no expense to keep residential customers with heat. Gas supplies to non-residential customers may also be able to purchase gas at a higher price. Curtailment to residential customers, however, can have life threatening consequences. However, weather conditions and thus the demand for gas are very difficult to predict in advance. Even with subjective probability estimates, LDC managers must assume a substantial amount of risk in making any but the most conservative demand forecasts.

An optimal procurement strategy that seeks to minimize the cost of providing a secure gas supply must simultaneously consider all purchase options, deliverability, and weather conditions. This paper demonstrates that while deliverability is typically excluded from the decision making process, it is a key part of this process. The remainder of this paper is organized as follows. The next section describes the relationship of the gas procurement problem to other problems in inventory management, and how optimization models have in the past been used to solve this 
problem. This is followed by a description of the planning process faced by LDCs, and of an optimization model that can be used by LDCs to make procurement decisions. The model is implemented using data from an actual LDC for whom it was used to influence their gas procurement strategy. A base case scenario is solved and sensitivity analysis performed to demonstrate the effects of changes in constraints and demand characteristics on optimal system cost and the optimal level of deliverability. Finally, the implications of the results and the relevance of the model to other applications are discussed.

\section{LITERATURE REVIEW}

The procurement/inventory problem faced by LDCs differs from those addressed by traditional inventory models, including those based on the economic order quantity (EOQ), in several regards. Most models assume that price is known in advance or can be estimated [11]. Models also exist that incorporate known price decreases (e.g., [8]) and in particular, known price increases, the so called Announced Price Increase Problem (e.g., [1]). However, when an LDC makes purchase decisions, it does not know what firm and spot prices will be for future quarters, only that spot prices will probably differ from firm prices. Spot prices could be lower than firm prices if the market softens, but they could also be considerably higher if a particularly severe cold spell strikes. The amount available for supply is also generally assumed to be known with certainty [11]. Silver [9] extended the EOQ model to consider the case where the amount supplied need not equal the order quantity, but where the EOQ represents the basis for order quantities. LDCs are faced with the problem that the amount of gas available for purchase at the spot price is not known in advance and cannot be predicted, yet spot purchases may represent the lowest cost way to obtain supply. Silver and Jain [10] considered the case where a buyer may reserve future supplier capacity when this is uncertain by paying a premium. At the appropriate time, the buyer may then purchase any quantity not in excess of the capacity reserved. This however does not fully capture the situation faced by the LDC. Quantities of gas available at some spot price are generally assumed, though this price may be very high and the quantity limited. However, if demand cannot be met, the consequences can be severe.

In addition to the usual inventory related costs (e.g., acquisition, setup/order, and holding costs), LDCs are faced with the cost of deliverability. A fixed cost is incurred for the right to withdraw/inject up to a contracted amount of gas each day. Typically, only a limited number of discrete levels of deliverability can be purchased, yielding a multiple setup cost structure similar to that faced by transportation companies which pay a charge for each rail car or container used [3]. Unlike these costs, however, the cost of deliverability is often tied to the amount of storage capacity purchased since deliverability rates are typically, ,expressed as a percentage of the storage capacity contracted for by the LDC.

An assumption made by most inventory models is that demand is independent of price. When they ,,make gas purchases, LDCs are not purchasing to meet a specific level of demand, rather 
their intent is to ensure that they can meet any prevailing demand pattern at the lowest cost. With gas prices subject to change each day, and with spot prices lower than firm prices in warm months, there may be some incentive for LDCs to increase their purchases when prices are low, and store the gas. This requires that they have adequate storage capacity and a rate of deliverability that allows them to build up and run down their inventory at an appropriate rate. Some models consider the case where demand is price dependent (e.g., [2]), though these are not faced with the deliverability considerations encountered here.

The problem of formulating gas procurement strategies has previously been addressed using mathematical programming. Avery et al., [4] developed a decision support system that incorporates a linear programming model used by LDCs in making gas supply, transportation, and storage decisions. They outlined four issues that LDCs must consider: the balance between firm contract and spot market gas purchases and between firm and interruptible pipeline reservations for transportation, storage capacity, deliverability levels, and marketing decisions about firm and interruptible sales offerings. Although deliverability was addressed, the rate was assumed to be fixed rather than a decision variable. To account for uncertainties in demand, a sub model with peak day/hour constraints was generated in parallel to the main model for the time period being addressed, and independent model results obtained for a number of demand/price scenarios.

Knowles [7] described a large scale stochastic, chance constrained model, focusing on two types of decisions: entitlement decisions that define the characteristics of gas supply contracts, and dispatching decisions regarding how the gas supply is managed to meet demand under different weather patterns. However, while the model incorporated deliverability as a decision variable, the study did not address the role of deliverability in securing the gas supply, nor the tradeoffs LDCs must make between cost and security.

\section{DECISIONS IN LDC GAS SUPPLY PLANNING}

Decisions made by LDCs can be categorized according to the time frame in which they are made: annual, monthly, daily, and mid daily. Annual decisions are purely strategic, mid daily ones are purely operational, while there is a mix of strategic and operational considerations in monthly and daily decisions. To provide a context for understanding the model to be presented and the role of deliverability, consider the decisions made by LDCs at various points in time:

- Annual decisions: Annual firm gas purchases, reservations for firm pipeline transportation, maximum level of storage capacity, and maximum amount of daily deliverability to and from storage. These are strategic decisions made for contract structuring purposes with the goal of minimizing costs while meeting estimated demand on the system. 
- Monthly decisions: Monthly firm gas purchases (in addition to annual purchases) and monthly firm gas purchases (an option can be bought guaranteeing delivery of gas, if needed). Possibilities might also exist to sell some excess pipeline capacity. These are also primarily strategic decisions made with the goal of cost minimization subject to demand.

- Daily decisions: Daily spot market gas purchases, daily interruptible transportation levels, and storage injection and withdrawal amounts. These are primarily operational decisions made to meet daily system demand. If mid-day corrections in purchase, transportation, and/or storage decisions are allowed, then there is a strategic aspect to these decisions.

- Mid-day decisions: The rate of injection/withdrawal can be amended, subject to constraints, from the previous days specified deliverability, spot purchases can be verified and possibly altered, and some latitude may be possible regarding firm/interruptible pipeline usage. These decisions are almost exclusively made to meet demand requirements for a particular day or to relieve the LDC from some firm commitment (usually transportation) for that day, if allowed.

\section{MODEL DESCRIPTION}

The model presented here focuses on decisions of a strategic nature. It is formulated from an annual quarterly perspective with the goal of minimizing cost while ensuring a secure supply of gas. This is consistent with the criteria used by LDC management, and the cost and security considerations described earlier. We specifically address the issue of what happens to system cost and the level of deliverability as important security constraints are altered.

The annual decisions considered are the amounts of firm contract gas purchases and firm pipeline transportation, the maximum amount of storage space to reserve, and the level of deliverability to purchase. The quarterly decisions considered are the amounts of spot market gas and interruptible transportation to purchase, and the rates of deliverability to use. Deliverability is defined as a daily rate and assumed to be constant throughout the quarter. To simplify the use of the model and interpretation of results, all costs and decision variable values are defined on an average daily basis.

Although aggregating on a quarterly basis reduces the complexity of the model, it does imply simplification of the actual decisions faced by LDC managers. For example, within a quarter there is likely to be monthly if not daily variation in the price and availability of gas and transportation as well as in weather and thus demand patterns. This also suggests that deliverability levels will vary within a quarter. However, given the focus on decision making of a strategic nature and the objective of examining the role of deliverability on cost and security concerns, this is not considered to be a significant limitation. 
Gas is supplied from a natural gas field and can be shipped either directly to a city or to a storage facility and later shipped to the city. One pipeline is assumed to exist between each pair of gas field, storage facility, and city. There are no limitations on the type of transportation that can be used to ship gas. At the stage of the planning process where this model would be used, the rate of deliverability is not tied directly to the level of storage. Most storage facilities directly link the two levels, the daily rate of deliverability being determined as a fixed percentage of storage capacity. The LDC may thus have no choice regarding the rate of deliverability purchased. However, in many locations, LDCs can store gas at more than one facility. By signing appropriate contracts with multiple storage facilities offering different deliverability rates and storing corresponding levels of gas at each, the LDC can obtain the rate of deliverability it requires while simultaneously diversifying • any $\bullet$ risks of having a sole storage option. Assuming transportation and storage options to be homogeneous and having only single pipelines again represents a simplification of the actual problem faced by LDCs. As indicated previously, given the objectives of the model, this is not a significant concern.

Demand patterns faced by LDCs are inherently uncertainty. This is modeled by specifying four discrete demand scenarios for winter, corresponding to a warm, average, cold, and very cold winter, similar to Knowles [7]. Each has an associated likelihood of occurrence. These are discussed further in the next section. Variation in load (demand) in non-winter quarters is so small compared to that in winter that loads can be assumed to be known with relative certainty. It is when uncertainties in weather affect winter load that security and cost issues are of greater significance. The objective of the proposed model is to minimize the expected cost over all scenarios of the LDCs purchase, transportation, storage, and deliverability decisions.

The elements of the model are summarized below. A complete mathematical formulation is provided in Appendix I.

\section{Parameters}

Annual costs of

- firm transportation

- storage space

- deliverability

Quarterly costs of

- firm and spot gas purchases

- firm and interruptible transportation

- injections and withdrawals

- gas inventory

Input Values

- maximum amount of spot purchases

- minimum amount of firm transportation 
- quarterly demand

- probabilities of weather scenarios

- beginning and year ending inventory

\section{Decision Variables}

Annual level of

- firm gas purchases

- firm transportation purchases

Quarterly level of

- firm and spot gas purchases

- firm and interruptible transportation purchases

- injections and withdrawals

- ending inventory

Maximum level of

- $\quad$ storage space

- deliverability

\section{Objective Function}

Minimize expected cost/day of annual costs for firm transportation, storage space, and deliverability, and quarterly costs for firm and spot purchases, firm and interruptible transportation, storage injections and withdrawals, and inventory

\section{Constraints}

Requirements:

- annual firm transportation level must meet or exceed the required minimum level

- firm purchases must be constant for each period in the same contract year

- the amount of gas delivered to the city must meet demand

- the year ending inventory level must meet the required minimum level Limitations:

- $\quad$ spot purchases cannot exceed the maximum spot purchase level

- the amount of firm transportation used cannot exceed the annual firm transportation level

- daily injection amounts cannot exceed the maximum daily deliverability level

- daily withdrawal amounts cannot exceed the maximum daily deliverability level

- ending storage levels cannot exceed the maximum storage level

Gas flow conservation:

- all gas purchases must be delivered from the gas field to either the city or the storage facility

- all gas transported to/from the storage facility via either firm or interruptible transportation must injected into/withdrawn from storage 
- ending storage levels must equal the beginning storage level plus the amount of gas injected into storage minus the amount withdrawn

\section{CASE STUDY: THE HUNTSVILLE LDC}

The LDC at Huntsville, Alabama was used to demonstrate the modeling approach. It is a medium sized LDC with characteristics typical of many LDCs which serve residential areas. This section describes how data for the model was obtained from historical data (for the period 1991 94). A base case of the model was solved using this data and sensitivity analyses carried out on the level of firm transportation mandated, the availability of spot market purchases, and the probabilities of winter demand levels. These show the relationships of firm transportation levels, spot market purchases, and demand uncertainty to the deliverability decision and system cost. To examine the importance of deliverability when its cost changes, a second version of the model was also implemented in which two storage options are available and the cost of the more attractive option increases.

\section{Costs and model inputs:}

The Huntsville LDC is billed monthly for its gas purchases, transportation, storage capacity, and deliverability levels. Price/cost information for the three quarters with deterministic demand (summer, fall, and spring) and for the average winter quarter was obtained from invoices for December 1993 to November 1994. Information for the other winter scenarios (warm, cold, and very cold) was obtained from fuel managers, based on their experience of cost behavior. Historical cost data for these scenarios is not useful because of recent deregulation rulings that have affected the industry (e.g., [13]). Since wellhead gas prices can vary from 1.50 to 3.00 per mcf (thousand cubic feet) depending on the weather, a cursory analysis of spot market prices suggested an estimated cost that is $75 \%$ of observed cost during a warm winter, $125 \%$ of observed cost during a cold winter, and $200 \%$ of observed cost during a very cold winter. However, if transportation became extremely limited, experts believed transportation costs in a competitive, deregulated market might rise, placing a premium on the ability to transport gas, and thereby also on the ability to withdraw gas from storage. The analyses presented may thus understate the value and importance of deliverability.

To address the problem of uncertain demand, Huntsville's monthly demand was forecast using a two-step procedure. First, demand was estimated using a nonlinear regression model with the independent variables being Huntsville's heating degree days lagged by one day, a dummy variable for the winter months (December to February), and time. Details are provided in Appendix II. Heating degree days are defined to be the difference between the daily temperature and a temperature of $65 \mathrm{~F}(18.3 \mathrm{C})$, for those days with temperatures below $65 \mathrm{~F}$. The model obtained explained $97 \%$ of the variation in demand. Monthly estimates were aggregated into quarterly ones to be used in the model. 
In the second step, the last twenty years of Huntsville winter temperatures were examined to identify the frequency of winters of varying severity. This showed that one winter in twenty was very cold (average daily temperature, ADT, more than two standard deviations lower than the mean), four were much colder than average (ADT more than one standard deviation lower than the mean), half were about average (ADT within one standard deviation of the mean), and five were slightly warmer than average (ADT between one and two standard deviations above the mean). Based on these observations, the probabilities of occurrence of each winter scenario were established as $0.25,0.5,0.2$, and 0.05 for warm, average, cold, and very cold winters respectively. The average daily temperature for each winter scenario was then incorporated in the regression equation and demand estimated. This yielded average daily demands of 25,724, $30,132,34,500$, and 38,130 mcf for the warm, average, cold and very cold winters respectively. The estimated average daily demands were 8,118, 14,463, and 16,036 mcf in the summer, fall, and spring quarters respectively.

To define a base or reference case which involves a reasonable, minimum level of security in the gas supply yet still leaves the LDC exposed to some risk, certain assumptions were made. Firm transportation must account for at least $70 \%$ of Huntsville's peak winter quarter demand, or 26,691 mcf/day, and spot purchases cannot exceed 20,000 mcf/day during that quarter. There is no need to constrain spot purchases in other quarters. Since the LDC will be forced to buy firm gas if spot gas is not available in the period with the highest demand, firm gas will also be available in other time periods. These assumptions imply that $30 \%$ of demand is left unprotected in the event that interruptible transportation is not available, and that the LDC still faces some possibility of not meeting demand using spot purchases. It is also assumed that beginning and ending inventory levels are 800,000 mcf, a level recently observed at the end of a typical winter. The intent of this case is not to exactly replicate LDC performance, rather to begin analysis of the LDC decision making process at a reasonable starting point which can then be used as a basis for further discussion.

\section{Huntsville LDC Results:}

The optimal solution indicates that the LDC requires a maximum storage capacity of 901,080 mcf and a maximum deliverability level of 8,889 mcf/day. In other words, the daily rate of deliverability is $8,889 / 901,080$ or approximately $1 / 101$ of maximum storage capacity. The LDC should contract for firm purchases of 9,241 mcf/day, and a firm transportation level of 26,691 $\mathrm{mcf} /$ day. This is the minimum level required by the constraint on firm transportation. Interruptible transportation is only used during the winter, with levels varying from $156 \mathrm{mcf} /$ day during a warm winter up to $8,889 \mathrm{mcf} /$ day during a very cold winter. Spot market purchases only reach the upper limit of 20,000 mcf/day during a very cold winter though they should be made in every quarter except summer. The LDC should withdraw gas from storage during the fall and winter except when the winter is warm, and inject gas into storage to replenish inventory levels 
during the summer, winter, if it is warm, and spring unless the preceding winter was warm. The solution yields a cost of 49,074/day.

From our discussion of the LDC decision process, it is clear that there are two primary events that can preclude an LDC from being able to deliver gas to its customers (barring natural or terrorist disasters): not having enough gas through purchases and/or inventory, or not having enough transportation to deliver gas to the city. Availability of firm transportation is particularly critical on a cold day since interruptible transportation may not be available. If the availability of firm transportation is inadequate and interruptible transportation cannot be purchased, nothing can prevent curtailment of gas supply to customers.

To investigate the impact of increasing security by raising purchases of firm transportation and to examine the impact on optimal deliverability rates of firm transportation levels, the level of firm transportation required was varied from $10 \%$ to $100 \%$ of peak demand during a very cold winter. This analysis allows an LDC decision maker to balance the benefits and risks of reducing costs by lowering firm transportation requirement with the added security and costs of a higher requirement. Results are presented in Table 1. Parametric range analysis was also carried out on the right hand side of this constraint to determine which values cause a change in the shadow price and optimal basis. Figures 1 and 2 illustrate optimal system cost and level of deliverability for this analysis. Whereas decisions regarding firm transportation and deliverability levels are often made independently, the results show that setting a minimum level of firm transportation requires choosing a corresponding level of deliverability if system costs are to be minimized. While system cost increases as the level of required firm transportation increases, the level of deliverability required first decreases to a minimum of 5,258 mcf/day at transportation levels between 12,872 and 20,516 mcf/day before increasing. From these results, the LDC decision maker can see the cost of changing the level of security obtained from firm transportation and how the optimal level of deliverability varies.

To analyze the effects of limited availability of gas on a spot basis, the level of firm transportation required was set at $70 \%$ of maximum peak demand and the level of spot purchases that could be made was varied. Results for five specific cases are shown in Table 2. The results of parametric range analysis for optimal cost and deliverability are shown in Figures 3 and 4. As expected, both cost and the required level of deliverability decrease as spot gas becomes more available. When this occurs, there is less to be obtained from purchasing gas on firm contracts or withdrawing gas from storage. The cost differential between buying 5,000 mcf/day on a spot basis versus $25,000 \mathrm{mcf} /$ day is only 830 /day. However, to keep this cost differential low as spot purchases vary, the optimal level of deliverability must increase from $8,889 \mathrm{mcf} /$ day to more than 17,000 mcf/day. This shows that deliverability can substitute for gas purchases in providing system security under certain conditions. In contrast, for a similar difference in levels of firm transportation, the difference in cost is more than 2,500/day (Figure 2). In general, the optimal 
level of deliverability is more sensitive to the availability of spot purchases than to the level of required firm transportation, though the LDC has more control over the latter.

The base case model was also run with different probabilities of warm, average, cold, and very cold winter quarters. Table 3 shows results for five cases where the probability of having a very cold winter ranges from 0.05 to 0.6 . This shows the sensitivity of the optimal level of deliverability to weather conditions. The optimal level of deliverability g s up to $38,130 \mathrm{mcf} / \mathrm{day}$, the same as the required level of firm transportation, as the likelihood of a very cold winter increases.

The last analysis extends the model to consider the impact of having two storage facilities available. The deliverability levels were established at 1/10 and 1/150 of maximum storage capacity for the two storage facilities referred to as $\mathrm{X}$ and $\mathrm{Y}$, respectively. These levels were recently available to the Huntsville LDC. Costs of storage capacity were assumed to be equal at the two facilities. Initially, the cost of deliverability was also set at the same level at each facility, at $2.84 / \mathrm{mcf}$. Under these conditions, the optimal decision is to store all gas at facility $\mathrm{X}$, the one with the higher deliverability. To examine the impact on storage decisions of increasing the cost of deliverability at the more attractive facility, the cost of deliverability at facility $\mathrm{X}$ was increased while keeping the cost constant for facility Y. Results are provided in Table 4. As deliverability becomes more expensive at facility $\mathrm{X}$, the optimal level of deliverability decreases at that facility while increasing at facility $Y$. Even when deliverability at facility $X$ costs twice that at facility $\mathrm{Y}$, the least cost combination still involves utilizing both. Only when the cost at facility $\mathrm{X}$ is over $7.00 / \mathrm{mcf}$ does the optimal decision become to store all gas in the facility with the lower deliverability rate. This analysis makes it possible for LDC decision makers to determine how much value to place on the two deliverability options. It was recently used with the Huntsville LDC to convince them that having two storage options is slightly less expensive than having one, but more importantly, that reducing the number of storage options severely impacts system security. LDC managers had focused on the total amount of storage and, as a result, concluded that there was sufficient storage capacity at a single location. The analysis presented here showed them that over a range of scenarios, the optimal level of deliverability, which affects both costs and security, fell between the levels that could be obtained from using only one of the two storage options under consideration, and that this level could be obtained by having storage contracts with each facility.

\section{CONCLUSIONS}

The Huntsville LDC case study demonstrates that more effective gas procurement strategies can be obtained by LDCs through the use of the proposed model. In particular, it indicates that the optimal level of deliverability is very sensitive to changes in several important model parameters which affect system security. It also shows that in some cases, system cost is not greatly affected by varying basic model assumptions pertaining to security as long as the level of deliverability is 
appropriately modified in the new context. Although LDCs are usually offered a specified rate of deliverability, they should negotiate for an optimal rate or consider the use of a secondary storage option if that allows them to obtain a rate of deliverability closer to the optimal rate.

Although the model presented here focuses on strategic decisions, the model could be extended to address decisions at an operational level. Using a daily time frame instead of quarters, it would be possible to capture the impact of daily fluctuations in, for example, gas prices and availability, weather conditions, and thus demand for gas. This would also make it possible to examine how to plan for extremely cold days, particularly when these do not coincide with extremely cold quarters. Further disaggregation would also make it possible to address differences in storage and/or transportation options, for example, differences in capacities and costs of storage options, multiple pipelines, and lengths of contracts.

The conclusions from this work may also have applications in the development of the United States Strategic Petroleum Reserve. This reserve is a government owned storage facility for oil which is to be released in the event of a national oil shortage. Several articles have appeared in the literature concerning this facility's impact on private storage levels [14], specifying the "trigger" mechanism for releasing the oil [6], and determining the size of the facility [5][12]. Although they indicate that some thought has been given to the question of how fast to fill the reserve, the issue of deliverability has not been specifically addressed.

\section{REFERENCES}

1. Arcelus FJ and Srinivasan G (1993) Generalizing the Announced Price Increase Problem. Decision Sciences, 24(4), 847866.

2. Arcelus FJ and Srinivasan G (1987) Inventory Policies Under Various Optimizing Criteria and Variable Markup Rates. Management Science, 33(6), 756762.

3. Aucamp DC (1982) Nonlinear Freight Costs in the EOQ Problem. European Journal of Operational Research, 9, 61, 63.

4. Avery W, Brown G, Rosenkranz J and Wood K (1992) Optimization of Purchase, Storage and Transmission Contracts for Natural Gas Utilities. Operations Research, 40(3), 446462.

5. Balas E (1979) How Large Should It Be?. Graduate School of Industrial Management, Carnegie Mellon University, Pittsburgh, PA.

6. Devarajan S and Hubbard R (1984) Drawing Down the SPR: The Case for Selling Futures Contracts. In Alm A and Weiner R, eds., Oil Shock: Policy Response and Implementation, Ballinger, Cambridge, MA.

7. Knowles T (1994) A Stochastic Programming Model for Gas Supply Planning. Proceedings of the National Decision Sciences Institute Conference, 12541256.

8. Lev B and Weiss HJ (1990) Inventory Models with Cost Changes. Operations Research, 38(1), 5363. 
9. Silver EA (1976) Establishing the Order Quantity when the Amount Received is Uncertain. INFOR, 14(1), 3239.

10. Silver EA and Jain K (1994) Some Ideas Regarding Reserving Supplier Capacity and Selecting Replenishment Quantities in a Project Context. International Journal of Production Economics, 35, 177182.

11. Silver EA and Petersen R (1985) Decision Systems for Inventory Management and Production Planning. John Wiley \& Sons.

12. Teisberg T (1980) A Dynamic Programming Model of the US SPR. MIT Energy Lab, Cambridge, MA.

13. Walls W (1995) An Econometric Analysis of the Market for Natural Gas Futures. The Energy Journal, 16 (1), 7184.

14. Wright B and William J (1982) The Roles of Public and Private Storage in Managing an Oil Import Disruption. Bell Journal of Economics, 13(2), 341353.

Acknowledgements - The authors wish to thank three anonymous referees whose comments and insights helped to improve an earlier version of this paper.

\section{Appendix I}

\section{Model Formulation}

Indices

$i \epsilon T=\{1,2,3 \mathrm{~A}, 3 \mathrm{~B}, 3 \mathrm{C}, 3 \mathrm{D}, 4 \mathrm{~A}, 4 \mathrm{~B}, 4 \mathrm{C}, 4 \mathrm{D}\}$ for the four quarters of the year where $1=$ summer

$2=$ fall $=$ warm winter

$3 \mathrm{~B}=$ average winter

$3 \mathrm{C}=$ cold winter

$3 \mathrm{D}=$ very cold winter

$4 \mathrm{~A}=$ spring after warm winter

$4 B=$ spring after average winter

$4 \mathrm{C}=$ spring after cold winter 
$4 \mathrm{D}=$ spring very cold winter

\section{Parameters}

$\mathrm{cf}=$ cost of firm transportation purchases on annual contract $(\$ / \mathrm{mcf})$

cs $=$ cost of storage space on annual contract $(\$ / \mathrm{mcf})$

$\mathrm{cd}=$ cost of deliverability on annual contract $(\$ / \mathrm{mcf})$

$\mathrm{fp}_{\mathrm{i}}=$ cost of firm gas purchases in period $\mathrm{i}(\$ / \mathrm{mcf})$

$\mathrm{sp}_{\mathrm{i}}=$ cost of spot gas purchases in period $\mathrm{i}(\$ / \mathrm{mcf})$

$\mathrm{fta}_{\mathrm{i}}=$ cost of firm transportation purchases from gas field to city in period i $(\$ / \mathrm{mcf})$

$\mathrm{ftas}_{\mathrm{i}}=$ cost of firm transportation purchases from gas field to storage in period $\mathrm{i}(\$ / \mathrm{mcf})$

$\mathrm{ftsc}_{\mathrm{i}}=$ cost of firm transportation purchases from storage to city in period $\mathrm{i}(\$ / \mathrm{mcf})$

$i a_{i}=$ cost of interruptible transportation purchases from gas field to city in period $\mathrm{i}$

$(\$ / \mathrm{mcf})$

itas $_{i}=$ cost of interruptible transportation purchases from gas field to storage in period $\mathrm{i}$

$(\$ / \mathrm{mcf})$

itsc $_{i}=$ cost of interruptible transportation purchases from storage to city in period $\mathrm{i}$

(\$/mcf)

$\mathrm{si}_{\mathrm{i}}=$ cost of injecting gas into storage in period $\mathrm{i}(\$ / \mathrm{mcf})$

$\mathrm{sw}_{\mathrm{i}}=$ cost of withdrawing gas from storage in period $\mathrm{i}(\$ / \mathrm{mcf})$

$\mathrm{v}_{\mathrm{i}}=$ cost of storing gas in period $\mathrm{i}(\$ / \mathrm{mcf})$

$\mathrm{d}_{\mathrm{i}}=$ average daily demand in period $\mathrm{i}(\mathrm{mcf})$

$\mathrm{p}_{\mathrm{i}}=$ probability that year contains period of type $\mathrm{i}(\mathrm{pi}=1$ for periods 1 and 2$)$

$\mathrm{sp} 3 \mathrm{~d}=$ maximum spot gas purchase quantity in period $3 \mathrm{D}(\mathrm{mcf})$

$\mathrm{ftm}=$ minimum annual firm transportation purchase quantity (mcf)

$\mathrm{v}_{0}=$ inventory level at beginning of planning horizon (mcf)

$\mathrm{v}_{\mathrm{e}}=$ inventory level at end of planning horizon (mcf)

\section{Variables}

Note: The model is constructed from a daily perspective. Annual and quarterly costs and quantities are prorated to the corresponding mean daily value. With the exception of MSC (storage capacity purchased) and $\mathrm{Vi}$ (ending inventory in period i), all values are mean values/day.

ANCOSTS $=$ costs arising from annual decisions regarding firm transportation, storage space, and deliverability

$\mathrm{PER}_{\mathrm{i}}=(0.25$ of the $)$ costs arising from decisions in period $\mathrm{i}$ regarding firm and spot gas purchases, firm and interruptible transportation purchases, inventory, injection and withdrawal ( 0.25 is a weighting factor since each quarter is 0.25 of a year, FT $=$ firm transportation purchased on annual contract (mcf) $\mathrm{MDC}=$ maximum deliverability purchased on annual contract (mcf/day 
MSC $=$ maximum storage space purchased on annual contract (mcf)

$\mathrm{FP}_{\mathrm{i}}=$ firm gas purchases in period $\mathrm{i}(\mathrm{mcf})$

$\mathrm{SP}_{\mathrm{i}}=$ spot purchases of gas in period $\mathrm{i}(\mathrm{mcf})$

$\mathrm{SP} 3 \mathrm{D}=$ spot purchases of gas in a very cold winter (mcf)

FTA $_{i}=$ firm transportation purchases from gas field to city in period $\mathrm{i}$ (mcf)

FTAS $_{i}=$ firm transportation purchases from gas field to storage in period $\mathrm{i}(\mathrm{mcf})$

FTSC $_{i}=$ firm transportation purchases from storage to city in period $\mathrm{i}(\mathrm{mcf})$

ITA $_{i}=$ interruptible transportation purchases from gas field to city in period $\mathrm{i}(\mathrm{mcf})$

ITAS $_{\mathrm{i}}=$ interruptible transportation purchases from gas field to storage in period i (mcf)

ITSC $_{i}=$ interruptible transportation purchases from storage to city in period $\mathrm{i}(\mathrm{mcf})$

$\mathrm{SI}_{\mathrm{i}}=$ daily injections of gas into storage in period $\mathrm{i}(\mathrm{mcf})$

$\mathrm{SW}_{\mathrm{i}}=$ daily withdrawals of gas from storage in period $\mathrm{i}$ (mcf)

UFTA $_{i}=$ unused firm transportation in period $\mathrm{i}(\mathrm{mcf})$

$\mathrm{V}_{\mathrm{i}}=$ ending inventory in period $\mathrm{i}(\mathrm{mcf})$

\section{Objective function}

Minimize expected costs/day

where

$$
\text { minimize ANCOSTS }+\sum p_{i} P E R_{i}
$$

$$
\begin{gathered}
\text { ANCOSTS }=c f F T+c s M S C+c d M D C \\
P E R=f_{i} F P_{i}+s p_{i} S P_{i}+\text { fta }_{i} F T A_{i} \\
+ \text { ftas }_{i} F T A s_{i}+\text { ftsc }_{i} F T S C_{i}+i t a_{i} I T A_{i} \\
+ \text { itas }_{i} I T A S_{i}+i t s c_{i} I T S C_{i}+s i_{i} S I_{i} \\
+s w_{i} S W_{i}+v_{i} V_{i} \text { for } i \in T
\end{gathered}
$$

\section{Constraints}

a) Firm transportation purchased on an annual contract must meet or exceed the minimum required amount:

$$
F T>f t m
$$

b) Spot gas purchases in a very cold winter cannot exceed the maximum possible amount:

$$
S P 3 D<s p 3 d
$$

c) Firm gas purchases must be the same each period (even though annual contracts allow period costs to vary

$$
F P_{i-1}=F P_{i} \text { for } i \in T
$$

d) All gas purchases must be transported either to the city or to storage:

$$
\begin{gathered}
F P i+S P i=F T A i+F T A S i \\
+I T A i, \text { for } i \in T
\end{gathered}
$$


e) Total firm transportation purchases cannot exceed the annual firm transportation level:

$$
\begin{gathered}
F T A i+F T A S i+F T S C i+U F T A i \\
=F T \text { for } i \in T
\end{gathered}
$$

f) The amount of gas transported to the storage facility must equal the amount injected and the amount of gas transported from the storage facility must equal the amount withdrawn:

$$
\begin{array}{ll}
F T A S i+I T A S i=S I i & \text { for } i \epsilon T \\
F T S C i+I T S C i=S W i & \text { for } i \epsilon T
\end{array}
$$

g) The amount of gas transported to the city must meet demand:

$$
F T A i+F T S C i+I T A i+I T S C i \geq d \text { for } i \epsilon T
$$

h) Ending inventory equals beginning inventory plus injections minus withdrawals:

$$
\begin{gathered}
V_{i}=V_{i}+90 S I_{i}-90 S W \\
\text { for } i T(90=\text { days/quarter })
\end{gathered}
$$

i) Inventory requirements at beginning and end of planning horizon must be met:

$$
\begin{gathered}
V_{0}=v_{0} \\
V_{f} \geq v_{e} \text { for } j \in(4 A, 4 B, 4 C, 4 D)
\end{gathered}
$$

j) Inventory cannot exceed storage capacity:

$V_{i} \leq M S C$ for $i \in T$

k) The amount of gas injected into or withdrawn from storage cannot exceed the maximum deliverability level:

$$
\begin{aligned}
& S I_{i} \leq M D C \text { for } i \epsilon T \\
& S W_{i} \leq M D C \text { for } i \in T
\end{aligned}
$$




\section{Appendix II:}

\section{Estimation of Demand at the Huntsville LDC}

Nonlinear least squares regression was used to estimate the parameters in the equation

$$
\begin{gathered}
H U N L_{i}=a+b * H U N D D_{i} \\
+c * H U N H D D_{i-1}+d * T I M E \\
+e * \text { WINTE }+ \text { res }_{i}
\end{gathered}
$$

where

$$
\operatorname{res}_{i}=R H O * \operatorname{res}_{i-1}+\operatorname{err}_{i}
$$

$\mathrm{HUNL}_{\mathrm{i}}=$ Average daily demand in month

HUNHDD $_{\mathrm{i}}=$ Heating degree days in month

TIME = 1 in January 1991, 2 in February 1991, ..., July 1994

WINTER $=1$ in December, January, and February, and 0 elsewhere

$\mathrm{RES}_{\mathrm{i}}=$ estimated error from ordinary least squares regression in month $\mathrm{i}$

$\mathrm{RHO}=$ autoregression parameter

err $_{i}=$ error in month $\mathrm{i}$

Ordinary least squares regression yielded a Durbin Watson statistic which indicated the presence of auto correlated disturbances. The above procedure was thus used to correct for the violation of ordinary least squares regression assumptions.

Resulting estimates are:

Variable

Constant

HUNHDD $_{\mathrm{i}}$

HUNHDD i-1

TIME

WINTER

RHO

Adjusted r2: 0.971
Coefficient t-statistics

6392.70

1.24

14.77

2.38

0.20

.69

3.03

714.19

0.45

5.45

8.52 
Table 1. Sensitivity Analysis of Minimum Firm Transportation Purchase

Omega, Vol. 24, No. 5

Table 1. Sensitivity analysis of minimum firm transportation purchase

\begin{tabular}{|c|c|c|c|c|c|}
\hline $\begin{array}{l}\text { Minimum firm } \\
\text { transportation }(\mathrm{mcf} / \text { day })\end{array}$ & $\begin{array}{c}\% \text { of } \\
\text { maximum } \\
\text { demand }\end{array}$ & $\begin{array}{c}\text { Optimal } \\
\text { cost }(\$ / \text { day })\end{array}$ & $\begin{array}{c}\text { Optimal } \\
\text { deliverability (mcf/ } \\
\text { day) }\end{array}$ & $\begin{array}{l}\text { Optimal storage } \\
\text { capacity (mcf) }\end{array}$ & $\begin{array}{c}\text { Optimal } \\
\text { deliverability rate }\end{array}$ \\
\hline 3813 & $10 \%$ & 45,899 & 9450 & 850,540 & $1 / 90$ \\
\hline 7626 & $20 \%$ & 46,066 & 9450 & 850,540 & $1 / 90$ \\
\hline 11,439 & $30 \%$ & 46,299 & 6691 & $1,098,890$ & $1 / 164$ \\
\hline 15,252 & $40 \%$ & 46,724 & 5258 & $1,227,890$ & $1 / 233$ \\
\hline 19,065 & $50 \%$ & 47,443 & 5569 & $1,198,980$ & $1 / 215$ \\
\hline 22,878 & $60 \%$ & 48,225 & 6842 & $1,085,300$ & $1 / 158$ \\
\hline 26,691 & $70 \%$ & 49,074 & 8889 & 901,080 & $1 / 101$ \\
\hline 30,504 & $80 \%$ & 50,043 & 8889 & 901,080 & $1 / 101$ \\
\hline 34,317 & $90 \%$ & 51,178 & 8889 & 901,080 & $1 / 101$ \\
\hline 38,130 & $100 \%$ & 52,396 & 8889 & 901,080 & $1 / 101$ \\
\hline
\end{tabular}

Table 2. Sensitivity Analysis of Maximum Spot Gas Purchase

Table 2. Sensitivity analysis of maximum spot gas purchase

\begin{tabular}{ccccc}
\hline $\begin{array}{c}\text { Maximum spot gas } \\
\text { (mcf/day) }\end{array}$ & $\begin{array}{c}\text { Optimal cost (\$) } \\
\text { day) }\end{array}$ & $\begin{array}{c}\text { Optimal deliverability } \\
\text { (mcf/day) }\end{array}$ & $\begin{array}{c}\text { Optimal storage capacity } \\
\text { (mcf) }\end{array}$ & $\begin{array}{c}\text { Optimal } \\
\text { deliverability rate }\end{array}$ \\
\hline 25,000 & 49,063 & 8889 & 800,000 & $1 / 90$ \\
20,000 & 49,074 & 8889 & 901,080 & $1 / 101$ \\
15,000 & 49,213 & 10,856 & $1,174,040$ & $1 / 108$ \\
10,000 & 49,443 & 14,189 & $1,324,040$ & $1 / 93$ \\
5000 & 49,892 & 17,523 & $1,577,040$ & $1 / 90$ \\
\hline
\end{tabular}

Table 3. Sensitivity Analysis of Winter Severity

Table 3. Sensitivity analysis of winter severity

\begin{tabular}{ccccccc}
\hline \multicolumn{5}{c}{ Probabilities of winter severity } & Optimal cost (\$/day) & Optimal deliverability (mcf/day) \\
\cline { 1 - 3 } Warm & Average & Cold & Very cold & & 8889 \\
\cline { 1 - 3 } 0.25 & 0.5 & 0.2 & 0.05 & & 49,074 & 27,461 \\
0.25 & 0.25 & 0.25 & 0.25 & & 53,161 & 38,130 \\
0.4 & 0.1 & 0.1 & 0.4 & & 53,554 & 8889 \\
0.6 & 0.2 & 0.1 & 0.1 & 47,542 & 38,130 \\
0.1 & 0.1 & 0.2 & 0.6 & 56,127 & \\
\hline
\end{tabular}

Table 4. Sensitivity Analysis of Cost of Deliverability at Storage Facility X.

Table 4. Sensitivity analysis of cost of deliverability at storage facility $X$

\begin{tabular}{ccc}
\hline $\begin{array}{c}\text { Monthly deliverability cost at facility } X(\$ / \\
\mathrm{mcf})\end{array}$ & $\begin{array}{c}\text { Optimal deliverability at facility } X \text { (mcf/ } \\
\text { day) }\end{array}$ & $\begin{array}{c}\text { Optimal deliverability at facility } Y(\mathrm{mcf} / \\
\text { day })\end{array}$ \\
\hline $2.84-3.16$ & 18,130 & 0 \\
$3.17-4.33$ & 5006 & 0 \\
$4.34-6.50$ & 2912 & 2094 \\
$6.51-7.43$ & 967 & 4039 \\
$7.44+$ & 0 & 5006 \\
\hline
\end{tabular}


Figure 1. Relationship between minimum firm transportation purchase and optimal cost.

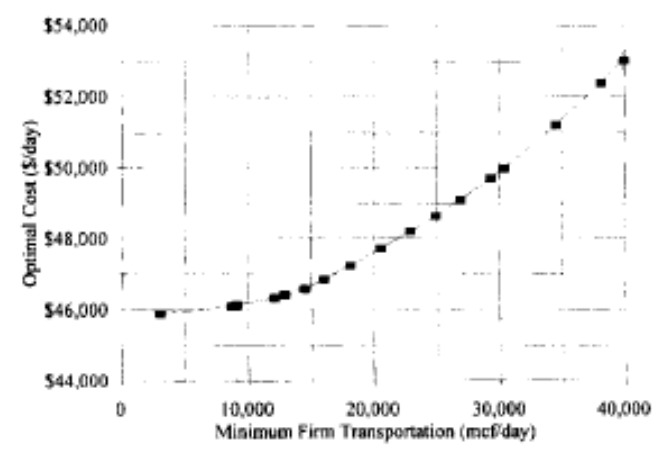

Figure 2. Relationship between minimum firm transportation purchase and optimal deliverability.

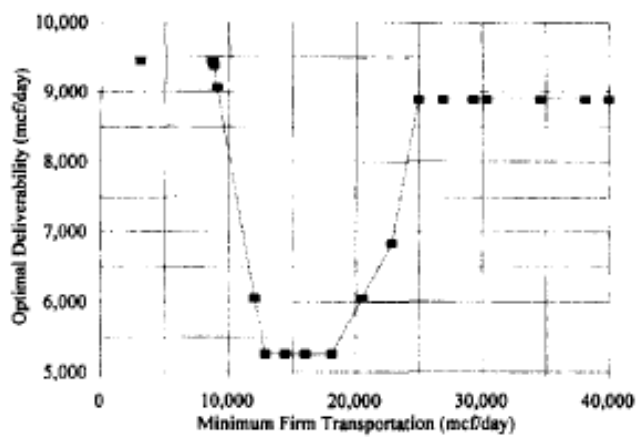

Figure 3. Relationship between maximum spot gas purchase and optimal cost.

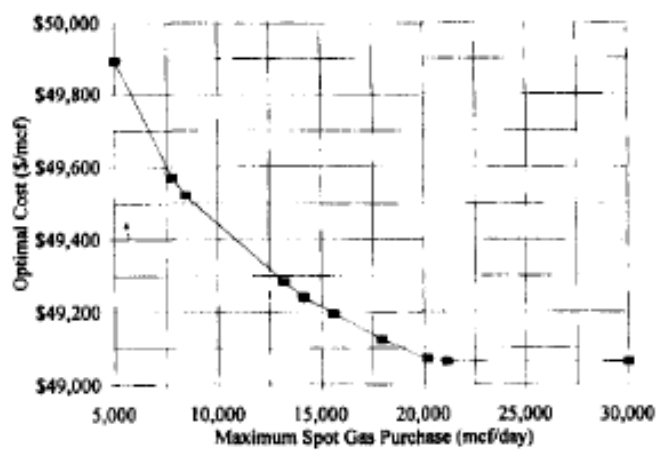

Figure 4. Relationship between maximum spot gas purchase and optimal deliverability. 


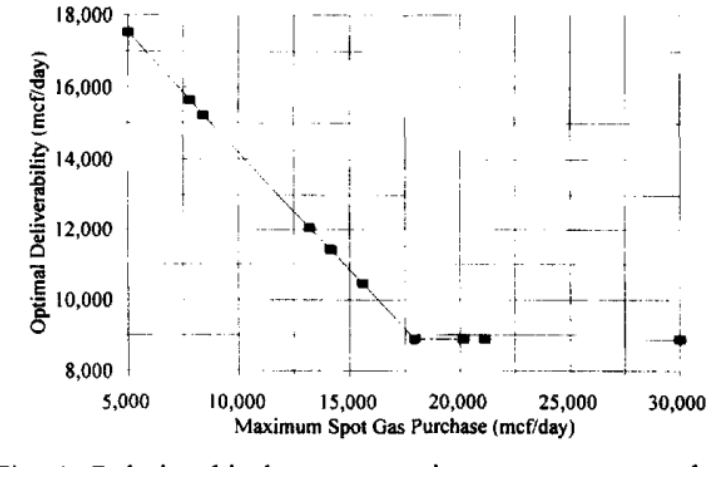

